\title{
SEGURANÇA QUÍMICA OU PROTEÇÃO ISOMÓRFICA? UMA ANÁLISE DA CRIAÇ̃̃O DO ANTEPROJETO DE LEI DE SUBSTÂNCIAS QỦIMICAS INDUSTRIAIS À LUZ DA TEORIA INSTITUCIONAL
}

Data de submissão: 10/04/2018 Aceite: 14/09/2018

Vanessa Barbosa ${ }^{1}$

Helene Mariko Ueno

\section{RESUMO}

O objetivo principal deste estudo foi identificar mecanismos isomórficos - coercitivo, mimético ou normativo - na construção do anteprojeto de lei para monitoramento e controle de substâncias químicas industriais, de forma a promover uma reflexão sobre as engrenagens de mudança que estão em curso e apontar desafios à governança em segurança química, em saúde e ambiente. Primeiramente, apresenta-se uma revisão bibliográfica sobre o contexto da segurança química no Brasil e no mundo. Em seguida, apresenta-se o referencial teórico com base na nova teoria institucional, que orienta a análise de conteúdo das 16 memórias de reuniões do grupo de trabalho instituído em maio de 2014 no âmbito da Comissão Nacional de Segurança Química (Conasq) para propor estratégias, arranjos institucionais e a minuta de legislação do anteprojeto de lei em questão. Os resultados foram categorizados, identificando-se processos e pressões isomórficas que incidem sobre as entidades representadas no grupo de trabalho, gerando-se, assim, um cenário preliminar da situação institucional e seus mecanismos de funcionamento que estão na gênese da nova normativa de segurança química.

Palavras-chave: Análise institucional; Segurança química; Saúde e Ambiente; Legislação.

1 Graduação em Comunicação Social - Habilitação em Jornalismo pela Universidade Federal do Rio de Janeiro (2005-2012), especialização em Direito Ambiental e Gestão Estratégica da Sustentabilidade pela Pontifica Universidade Católica de São Paulo (2012-2014) e mestranda pelo Programa de PósGraduação em Sustentabilidade da Escola de Artes, Ciências de Humanidades da Universidade de São Paulo (2017 até o presente).

E-mail: vanessabarbosa@usp.br

2 Graduação em Ciências Biológicas - Modalidade Médica pela Universidade Estadual Paulista Júlio de Mesquita Filho (1991-1994), graduação em Ciências Biológicas - Licenciatura pela Universidade Estadual Paulista Júlio de Mesquita Filho (1995-1996), mestrado em Saúde Pública pela Universidade de São Paulo (1997-2000) e doutorado em Saúde Pública pela Universidade de São Paulo (2001-2005). São Paulo-SP. Brasil.

E-mail:papoula@usp.br 


\section{INTRODUÇÃO: BREVE PANORAMA DE REGULAÇÃO DA INDÚSTRIA QUÍMICA}

A evolução da indústria química sintética a partir do século XIX permitiu o desenvolvimento de novas substâncias, produtos e materiais que visavam melhorias no cotidiano das pessoas e avanços socioeconômicos: produtos de cuidado pessoal e de higienização de ambientes, fármacos, alimentos, fertilizantes e defensivos de uso agrícola, embalagens, utensílios, entre outros produtos. Tais avanços trouxeram efeitos colaterais, refletidos em problemas ambientais, sociais e em saúde humana (LI e ANASTAS, 2012). O potencial de persistência ambiental e o uso frequente ou contínuo dos diversos produtos citados dificultam a caracterização da exposição humana e da biota. A literatura científica reúne evidências dos efeitos adversos causados pela exposição humana e ambiental às substâncias químicas, ainda que presentes em baixas concentrações nos produtos e nas matrizes ambientais, mas que muitas vezes se evidenciam no longo prazo, após anos de bioacumulação (COLBORN et al., 1996). A exposição a essas substâncias pode ocorrer pela via cutânea (BRAUSCH e RAND, 2011), pela via respiratória e pela via oral, por ingestão de alimentos e água contaminados (MITRO et al., 2016), ou mesmo pelo consumo de água potável, já que algumas delas não são eliminadas no tratamento convencional (ALMEIDA e WEBER 2005; FALCONER et al., 2006; GHISELLI e JARDIM, 2007). Os efeitos adversos incluem disfunções endócrinas e metabólicas, problemas reprodutivos e do desenvolvimento, redução da função do sistema imunológico, problemas comportamentais, entre outros (IPCS, 2012; WHO/UNEP 2013).

No que diz respeito ao controle e gestão de substâncias químicas, vários países estabeleceram estruturas e instrumentos regulatórios para disciplinar algumas aplicações e usos específicos para produtos como agrotóxicos, medicamentos e cosméticos. Porém, boa parte das substâncias utilizadas nos processos industriais não estão contempladas nessas normativas. Essa falta de controle introduz uma incerteza significativa sobre a verdadeira extensão dos riscos de produtos químicos para a saúde ambiental, notadamente quando se considera o pouco que se conhece sobre os possíveis efeitos sinérgicos que podem causar no ambiente (KORTENKAMP, 2007).

Diante dessa problemática, e tendo em vista a natureza indivisível do meio ambiente e sua ligação com as dimensões econômica e social, vários países, especialmente Estados Unidos, Canadá e Europa, têm avançado na discussão de novas legislações e revisão de antigas normas (ABELKOP e GRAHAM, 2007), a fim de definir valores de referência para limite de uso de substâncias químicas em produtos, encontrar substitutos mais seguros e, em última instância, banir o uso de substâncias com efeitos adversos evidenciados ou mesmo com base no princípio da precaução. Esses governos se mobilizam para estruturar um arcabouço legal e institucional que dê suporte às atividades de avaliação e controle dos riscos de produtos químicos, com a definição de competências e arranjos institucionais, formulação de políticas e programas nacionais para o gerenciamento dos riscos associados ao uso dessas substâncias.

Seguindo tendência mundial, o Brasil elaborou em 2016 o primeiro anteprojeto de lei para monitoramento e controle das substâncias químicas industriais1, ainda sujeito à aprovação no Congresso Nacional. O Ministério do Meio Ambiente estima que de 10 a 15 mil substâncias produzidas no país e importadas são colocadas no mercado nacional e utilizadas sem nenhum tipo de acompanhamento ou controle sistemático pelo poder público2, lacuna que o anteprojeto de lei visa preencher. Com faturamento de US\$ 112 bilhões, as empresas químicas empregam dois milhões de pessoas no Brasil e representam atualmente a sexta maior indústria do setor no mundo (PORTAL PLANALTO, 2016). Tamanha representatividade confere complexidade à discussão da temática, tendo em vista os múltiplos atores e interesses envolvidos e a articulação entre 
várias esferas organizacionais, conforme evidencia o documento de fundamentação e elementos técnicos relativos ao anteprojeto de lei (BRASIL. Ministério do Meio Ambiente, 2016):

As oportunidades decorrentes da gestão adequada de substâncias químicas industriais se estendem a uma maior aceitação dos produtos e serviços pelos consumidores, à redução de custos relativos à minimização de impactos e recuperação de danos ambientais e, ainda, representam uma oportunidade para a obtenção, pelo Brasil, de maiores investimentos estrangeiros, especialmente de países comprometidos com medidas de caráter preservacionista, decorrentes da melhoria nas ações de controle e fiscalização de substâncias químicas.

Neste artigo, considera-se que as crescentes pressões internacionais, a existência de lacunas no arcabouço legal nacional para o controle de substâncias químicas e a necessidade de se definir competências e arranjos institucionais para gestão dos riscos químicos criam um ambiente de incertezas e, ao mesmo tempo, de busca por legitimidade política e institucional, que prediz a ocorrência de mudanças isomórficas nos campos organizacionais, com reflexos no desenho da nova legislação. Dessa forma, objetiva-se analisar o processo de construção da normativa de segurança química à luz da nova teoria institucional, seguindo a abordagem de DiMaggio e Powell(2005), a partir da qual poderosas forças levam as organizações a se tornarem mais similares umas às outras, entre elas a competição para a legitimidade política e institucional, bem como a posição de mercado.

\section{ISOMORFISMO EM ESTUDOS ORGANIZACIONAIS}

As considerações das estruturas dos ambientes e seus efeitos sobre processos, formas e relações interorganizacionais na busca por legitimidade integram as pesquisas em teoria institucional, vertente que ganhou corpo nos últimos 30 anos nos estudos organizacionais (SCOTT, 2008). Em revisão da literatura, Melo Pereira (2012) observa que a teoria institucional é estudada no âmbito teórico e prático e em diversos contextos organizacionais, demonstrando que as organizações sentem a necessidade de padronizar comportamentos e disseminar a identidade organizacional entre os funcionários. Sob a perspectiva da teoria institucional, práticas organizacionais são "ações sociais regularizadas e recorrentes que continuamente constroem e reconstroem a organização como um sistema social espaço-temporalmente delimitado" (ALBUQUERQUE FILHO; MACHADO DA SILVA, 2009, p. 632). Entre as diversas perspectivas das teorias institucionais, DiMaggio e Powell (1991) se enquadram como novos institucionalistas, alinhados com a perspectiva estruturalista, focada na busca por estabilidade, resultados, dominação e continuidade do ambiente (BARRA, 2017). Sob essa ótica, a percepção de legitimidade de uma organização passa a ser associada pelo nível de incorporação de regras e crenças institucionalizadas por parte dela e que não estão necessariamente relacionadas à eficiência, mas a processos cognitivos e culturais perpetuados no campo organizacional, o que acaba por tornar as organizações cada vez mais similares entre si ou isomórficas, segundo DiMaggio e Powell (1991). Esses autores partem do conceito de isomorfismo de Hawley (1968), que traduz essa homogeneização organizacional, e propõem três mecanismos de isomorfismo institucional: coercitivo, mimético e normativo. Cada um envolve um processo separado, mas dois ou mais mecanismos podem operar simultaneamente, e os seus efeitos nem sempre são claramente identificáveis.

O isomorfismo coercitivo resulta de pressões formais ou informais exercidas por outras organizações das quais as organizações dependem e também por expectativas culturais da sociedade. As fontes de pressão incluem regulamentos e diretivas nacionais e internacionais, requisitos contratuais e técnicos, rituais em conformidade com instituições maiores, centralização de capital e centralização estatal. 
Outra forma de mudança organizacional isomórfica é a mimética, segundo a qual as organizações, de forma consciente ou inconsciente, tendem a tomar como modelo em seu campo outras organizações que elas percebem ser mais legítimas ou bem-sucedidas, refletindo suas práticas. As organizações podem se modelar por meio de transferência ou rotatividade de empregados ou, ainda, por meio de firmas de consultoria, organizações e associações industriais. Segundo os autores, a cópia de uma organização que parece mais bem sucedida e legítima é uma resposta à incerteza e uma forma de favorecer a legitimidade da organização, porque mostra sua atenção às melhores práticas.

O terceiro tipo de isomorfismo é o normativo, que envolve entidades profissionais capazes de regulamentar, impor e negociar regras e normas de acordo com os seus próprios interesses. Para os autores, dois aspectos relacionam profissionalização e isomorfismo: a) o apoio à educação formal e à legitimação e compartilhamento de uma base cognitiva de profissionais da área, associada ao consenso técnico; e b) a constituição de redes de profissionais pelos quais novos modelos organizacionais, normas e métodos de trabalho são difundidos. Por exemplo, quando membros de um determinado grupo profissional tentam definir métodos e práticas aplicáveis a uma determinada situação a partir de seu papel dentro da organização a que pertence. Dessa forma, a ação e tomada de decisão passam a se basear em conhecimento e experiências similares, que atravessam as organizações e difundem novos modelos com rapidez, processo observado na indústria química. Hoffman (1999) realizou um abrangente estudo sobre a evolução de normativas ambientais dentro da indústria química americana e concluiu que:

A lei é a manifestação visível dos atores relevantes no campo organizacional. Quem está autorizado a participar no processo legal reflete que possui uma voz jurídica na determinação das normas institucionais. A lei tem um impacto direto nas empresas e na ação, e lança uma luz reveladora sobre quais jogadores são relevantes na determinação dessa ação, proporcionando um sistema formal para que os atores se influenciem mutuamente (HOFFMAN, 1999, p.11).

Assumindo o isomorfismo na indústria química, no presente estudo buscamos identificar quais mecanismos isomórficos predominaram na criação do anteprojeto de lei para substâncias químicas - coercitivo, mimético ou normativo - e que setores pautaram essa agenda, de forma a promover uma reflexão crítica sobre as engrenagens de mudança institucional que estão em curso e apontar desafios à governança em segurança química, saúde e ambiente.

\section{METODOLOGIA}

Para alcançar o objetivo proposto, adotamos uma abordagem qualitativa. Conforme Godoy (1995), o enfoque qualitativo tem papel reconhecido entre as várias possibilidades de se estudar os fenômenos que envolvem os seres humanos e suas relações sociais nos mais diversos ambientes. No campo das ciências sociais, a pesquisa qualitativa abrange um conjunto de diferentes técnicas interpretativas que visam descrever e decodificar os componentes de um sistema complexo de significados (NEVES, 1996). Enquanto exercício de pesquisa, a abordagem qualitativa não se apresenta como uma proposta rigidamente estruturada, permitindo que a imaginação e a criatividade levem os investigadores a propor trabalhos que explorem novos enfoques (GODOY, 1995).

Buscando trazer contribuição importante no estudo do tema, procedemos, assim, à análise de conteúdo como método de investigação das 16 memórias das reuniões realizadas pelo "GT Regulação de Substâncias Químicas" instituído no âmbito da Comissão Nacional de Segurança Química (Conasq) para elaboração do anteprojeto de lei de substâncias químicas industriais durante o período de maio de 2014 a dezembro de 2015. O Grupo de Trabalho (GT) tinha como objetivo: 
Discutir e propor as estratégias, os arranjos institucionais e a minuta de legislação para estabelecer o controle do poder público sobre o universo de substâncias químicas que hoje são colocadas no mercado nacional sem a avaliação dos seus riscos ao meio ambiente e à saúde humana (BRASIL, Ministério do Meio Ambiente, 2016)

A análise de conteúdo fornece um método para avaliar sistematicamente, categorizar dados por codificação e identificar padrões. A presente análise se organizou em torno de três etapas: 1) préanálise; 2) exploração do material; 3) tratamento dos resultados, e interpretação (BARDIN, 1977). Na pré-análise foram realizadas leituras flutuantes do corpus das memórias das reuniões do GT, com o intuito de conhecer o contexto das discussões em pauta sobre segurança química e apreender e organizar de forma não estruturada aspectos importantes para as próximas fases de análise.

Na seleção das unidades de registro foram destacados segmentos do texto que podem ser caracterizados como uma ocorrência de evento de interesse para o objetivo da pesquisa, conforme proposto por Bardin (1977), relacionados tanto a falas individuais dos representantes quanto a comentários sem instituição definida na relatoria (comentários gerais do GT)Os segmentos destacados foram classificados segundo os três mecanismos de isomorfismo institucional de DiMaggio e Powell (2005): coercitivo, normativo ou mimético. A análise de conteúdo das memórias interpretou o corpus dos textos apenas à luz do referencial de codificação, embora ele possa estar ligado a uma variedade de outras questões. Entre os prós da categorização apriorística, Campos (2004) aponta as comodidades de um certo balizamento, o que permite ao pesquisador classificar diretamente suas unidades de análises dentro destas categorias. Por outro lado, categorias pré-definidas podem limitar a verificação de conteúdos que não estejam contemplados nessas categorias prévias, limitando a análise. Por fim, durante o tratamento dos resultados e interpretações, foi verificada a pertinência das categorias em questão para a construção do anteprojeto de lei de substâncias químicas industriais e a relação das categorias com os participantes do GT e suas respectivas instituições, com o objetivo de identificar quais aspectos isomórficos predominaram e quais grupos tiveram mais representação nas discussões, gerando-se, assim, um cenário preliminar da situação institucional em segurança química e seus mecanismos de funcionamento.

Considerando que a análise qualitativa busca uma apreensão de significados na fala dos sujeitos, associada ao contexto em que eles se inserem e delimitada pelo instrumental teórico do pesquisador (ALVES e SILVA, 1992), optou-se por destacar nos resultados segmentos de textos representativos das categorias de análise.

Participaram do GT representantes do setor público, privado, da sociedade civil e dos trabalhadores, provenientes das seguintes instituições: Ministério do Meio Ambiente (MMA, coordenador do grupo), Ministério da Indústria, Comércio Exterior e Serviços (MDIC), Ministério da Saúde (MS), Ministério de Minas e Energia, Instituto Brasileiro do Meio Ambiente e dos Recursos Naturais Renováveis (Ibama), Agência Nacional de Vigilância Sanitária (Anvisa), Fundação Jorge Duprat e Figueiredo (Fundacentro), Associação Brasileira da Indústria Química (Abiquim), Central Única dos Trabalhadores (CUT) e Fórum Brasileiro de ONGs e Movimentos Sociais para o Meio Ambiente e o Desenvolvimento (Fboms). Em alguns casos, mais de um representante de uma mesma instituição esteve presente.

\section{RESULTADOS}

Os resultados a seguir apresentados estão organizados conforme categoria de classificação, com destaque para segmentos de textos pertinentes do material analisado. 
Tabela 1 - Número de unidades referenciais classificadas por categoria de isomorfismo e entidade

\begin{tabular}{cccc}
\hline & Isomorfismo coercitivo & Isomorfismo mimético & Isomorfismo normativo \\
\hline Abiquim & - & 21 & 12 \\
Comentário geral do GT & 1 & 3 & 3 \\
Fboms & - & - & 1 \\
Fundacentro & 4 & 10 & 6 \\
Ibama & 1 & 1 & - \\
MDIC & - & 1 & 4 \\
MMA & 2 & 6 & - \\
\hline Total & 8 & 42 & 26
\end{tabular}

Fonte: Elaborada pelas autoras.

\title{
4.1 Categoria de isomorfismo coercitivo
}

Foram identificados ao longo das memórias analisadas 8 segmentos de textos que se enquadram nesta categoria: 1 associado a comentário geral do GT; 1 associado ao(s) representante(s) do lbama; 2 associados ao(s) representante(s) do MMA; e 4 associados ao(s) representante(s) da Fundacentro.

No comentário geral do GT, os participantes concordam que existem pressões crescentes exercidas sobre os países para que estes se organizem para melhor gerir substâncias e produtos químicos por meio da criação de legislação local específica. Entre os marcos internacionais importantes, destaca-se a Agenda 21, adotada na Conferência das Nações Unidas sobre Meio Ambiente e Desenvolvimento (Rio 92), que enfatiza a importância de estratégias nacionais e internacionais para gestão segura das substâncias químicas, incluindo a elaboração de legislação e mecanismos de implementação apropriados.

\begin{abstract}
Ainda resta muito a fazer para assegurar o manejo ecologicamente saudável das substâncias químicas tóxicas dentro dos princípios de desenvolvimento sustentável e de melhoria da qualidade de vida da humanidade. Dois dos principais problemas, em particular nos países em desenvolvimento, são: a) a falta de dados científicos para avaliar os riscos inerentes à utilização de numerosos produtos químicos; e b) a falta de recursos para avaliar os produtos químicos para os quais já dispomos de dados (AGENDA 21, Capítulo 19).
\end{abstract}

Para o manejo desses produtos, o documento propõe seis áreas de programas: a) expansão e aceleração da avaliação dos riscos dos produtos químicos à saúde e Meio Ambiente; b) harmonização da classificação e rotulagem de substâncias químicas; c) intercâmbio de informações sobre riscos dos produtos químicos; d) organização de programas de redução de riscos e promoção de alternativas; e) fortalecimento das capacidades e dos meios nacionais para a gestão de produtos químicos; f) prevenção do tráfico internacional ilícito dos produtos tóxicos e perigosos (UNCED, 1992).

Entre outros marcos importantes no cenário internacional que contribuíram para o avanço da Agenda 21 no Brasil e da agenda de segurança química, destacam-se a Cúpula de Joanesburgo (Rio +10) - que reiterou os acordos celebrados na Rio-92 e estabeleceu o compromisso para que os países desenvolvam, até 2020, seus sistemas de gerenciamento de substâncias químicas - e, mais tarde, em 2006, a primeira Conferência Internacional sobre Gerenciamento de Substâncias Químicas (ICCM-1), que originou a Estratégia Internacional para a Gestão de Substâncias Químicas (SAICM - Strategic Approach to International Chemicals Management), que recomenda ações para a formulação de políticas destinadas a fomentar a gestão de substâncias químicas pelos países signatários. 
Sob a ótica do isomorfismo coercitivo, todos esses marcos internacionais referem-se a pressões formais exercidas sobre uma organização, no caso o governo brasileiro, para a criação de um marco legal voltado à problemática da gestão de substâncias químicas.

Coordenadora das reuniões do GT de segurança química e diretora de Qualidade Ambiental do MMA, Letícia Reis destacou que na Assembleia das Nações Unidas do Programa das Nações Unidas para o Meio Ambiente (PNUMA), da qual participou, o tema principal de discussão foram os produtos químicos. Segundo ela, "haverá fontes de financiamento internacional para a agenda de Seurança Química. Antes, este financiamento contemplava apenas poluentes orgânicos persistentes (POPs) e agora contempla também toda a agenda de químicos." Em relação às pressões internas, Alberto da Rocha Neto, outro representante do MMA comentou que a entidade que representa quer ter conhecimento de todas as substâncias que circulam no país: "O conhecimento por parte do governo é importante para controle e até interações internacionais".

$\mathrm{O}$ isomorfismo coercitivo resulta de pressões formais e informais exercidas sobre organizações por outras organizações das quais elas dependem e pelas expectativas culturais da sociedade em que as organizações atuam (DIMAGGIO e POWELL, 2005). Esse movimento também pode ser verificado nas contribuições do representante da Fundacentro, Gilmar Trivelato, que assinalou questões relativas ao tratamento dado pela área trabalhista ao uso dos produtos químicos em ambientes de trabalho, citando marcos legais internacionais e expectativas do Ministério do Trabalho e Emprego (MTE): “É importante que a legislação trabalhista relacionada a produtos químicos - Convenções da OIT, Convenção 170 - seja analisada, pois esta é aplicável a todas as atividades econômicas nas quais se utilizam produtos químicos"; "Em termos de escopo, o Ministério do Trabalho recomenda que todos os produtos utilizados em ambiente de trabalho sejam classificados"; "Para o MTE todo produto que tenha uso em ambiente de trabalho precisa ser analisado, fichado e ter em seu rótulo as informações necessárias para seu uso seguro".

Apesar da baixa incidência do aspecto coercitivo do isomorfismo nas memórias das reuniões do GT de segurança química, entende-se que seu papel na gênesis do anteprojeto de lei é determinante, tendo em vista as pressões e expectativas nacionais e internacionais crescentes, que acabam por impor mudanças organizacionais.

\subsection{Categoria de isomorfismo mimético}

Durante as reuniões do GT, foram analisadas as legislações nacionais correlatas e modelos e experiências de outros países na gestão e controle de substâncias químicas, com o intuito de se verificar instrumentos e estruturas possíveis de serem aplicados à realidade brasileira, o que sinaliza um processo de isomorfismo mimético. DiMaggio e Powell (2005) entendem que as organizações assumem mecanismos de isomorfismo mimético diante de: a) problemas que não conseguem resolver sozinhas; b) tecnologias organizacionais pobres; c) ambiente de incertezas simbólicas. Buscando legitimação, elas acabariam por implementar processos e práticas semeIhantes aos de organizações vistas como mais bem posicionadas ou mais bem-sucedidas.

Ao todo, foram identificadas 42 unidades de registro que se enquadraram nesta categoria: 21 atribuídas ao(s) representantes da Abiquim; 10 ao(s)representante(s) da Fundacentro; 6 delas ao MMA; 3 a comentários gerais do grupo de trabalho; 1 ao(s) representante(s) do MDIC e 1 ao(s) representantes do Ibama. A seguir, apresentamos os principais sinais de isomorfismo mimético nos discursos dessas entidades. 


\section{Abiquim}

A Abiquim foi a organização que mais demonstrou postura de mimetizar práticas e normativas de organizações internacionais. Com frequência nos encontros do GT, a entidade tendeu a se balizar por modelos pré-existentes. Logo na primeira reunião, Nícia Fusaro Mourão, gerente de assuntos regulatórios e sustentabilidade da Abiquim, realizou apresentação intitulada "Inteligência Regulatória: alternativas para a gestão segura de produtos químicos no Brasil”, buscando elucidar os pontos principais de funcionamento do REACH (Registration, Evaluation, Authorisation of $\mathrm{CHemicals)} \mathrm{-} \mathrm{sistema} \mathrm{europeu} \mathrm{de} \mathrm{controle} \mathrm{de} \mathrm{substâncias} \mathrm{químicas} \mathrm{e} \mathrm{do} \mathrm{Challenge} \mathrm{-} \mathrm{siste-}$ ma canadense. Para a representante, "devemos usar como exemplo a legislação que já existe no mundo". Sua fala manifestou preocupação em relação a gastos para implementação da normativa. "Como vamos nos basear em conhecimentos oriundos de outros países, devemos na verdade racionalizar estes escopos para evitar gastos desnecessários, informações demasiadas, sem uso etc." As vantagens do comportamento mimético, em termos de economia de ações humanas, são consideráveis. Quando uma organização se vê frente a um problema com causas ambíguas e soluções pouco nítidas, uma abordagem problemística pode render uma solução viável com poucos gastos (CYERT e MARCH 1963 apud DIMAGGIO e POWELL, 2005, p.78). Nas reuniões seguintes, a representante da Abiquim apresentou critérios adotados pela União Europeia para classificar as substâncias químicas e suas escalas de perigo, na tentativa de pautar o escopo do anteprojeto. Algumas unidades relevantes que demonstram esse comportamento são destacadas a seguir:

- "Segundo Nícia (Abiquim)[...] os critérios para identificação da periculosidade das substâncias deveriam acompanhar o que tem caracterizado uma boa prática das legislações internacionais hoje vigentes, a exemplo do REACH, que foca os perigos crônicos à saúde humana e meio ambiente uma vez que os perigos agudos serão controlados no ambiente de trabalho".

- “... informou que a substância química é registrada no REACH, porém nem a mistura, nem os artigos são registrados. Embora estes não sejam registrados, o GHS determina a classificação tanto das substâncias, quanto das misturas, tendo o RE$\mathrm{ACH}$ adotado o GHS como sistema de rotulagem e de classificação de produtos perigosos. Já os artigos não entram no GHS. Ex. uma cadeira de plástico". GHS é acrônimo em inglês para The Globally Harmonized System of Classification and Labelling of Chemicals (Sistema Harmonizado Globalmente para a Classificação e Rotulagem de Produtos Químicos), um sistema internacional para definição dos perigos dos produtos químicos e criação de processos de classificação harmonizados. De especial importância para a elaboração do anteprojeto foi a definição dos termos "mistura" e "substância" e a necessidade de arbitrar um valor limite, como prevê uma decisão regulatória. A representante da Abiquim citou, mais uma vez, como referencial, a União Europeia: "Para o REACH o limite mínimo de concentração usualmente adotado é de $80 \%$ de uma substância na massa reacional; acima desse limite é considerado substancia pura. Água em qualquer proporção não entra como agente que altera a composição, logo, se tem um ácido, por exemplo, como menos de $80 \%$ da composição e o restante é água, ainda assim é considerado uma substância pura para o REACH." O referencial internacional também subsidiou as discussões para definir quais substâncias ficariam de fora do escopo da lei. Com relação a produtos da ati- 
vidade de mineração, por exemplo, a representante esclareceu que "na mineração somente se extrai e não se processa. Não há registros no REACH destes produtos minerais, quando são comercializados apenas in natura. Caso haja uma transformação química é preciso ser registrado no REACH." A certa altura, a representante do Fboms, Zuleica Nycz, sugeriu que o projeto de lei também incluísse os nanomateriais, cuja aplicação em cosméticos, fármacos e outros produtos tem gerado preocupação do ponto de vista da saúde ambiental. Sobre esse assunto, a representante da Abiquim manifestou sua discordância, tendo em vista que "outros países não estando tratando os nanomateriais no âmbito das leis gerais de químicos, mas sim em normas separadas e específicas". A fim de agilizar o processo de cadastro de substâncias, a representante informou que a Abiquim tem 975 empresas do setor químico mapeadas, representando $90 \%$ da produção brasileira e "que deveríamos pegar os dados que já existem para ganhar tempo com o processo".

No aspecto das responsabilidades institucionais para avaliação das substâncias químicas, o GT propôs a formação de um comitê técnico com a função de selecionar e avaliar substâncias químicas industriais constantes no cadastro quanto aos riscos à saúde humana e ambiental. A esse respeito, o representante do Ministério do Trabalho e Emprego sugeriu a participação do órgão governamental como parte da instância técnica, proposta que encontrou resistência também por pressões isomórficas de caráter mimético. "A Abiquim e o MMA reportaram que no Canadá apenas os setores de saúde e meio ambiente são responsáveis pela gestão das substâncias químicas, porém, aspectos socioeconômicos e a saúde laboral são levadas em consideração".

Diante do exposto, nota-se que a representante da Abiquim trabalha intensamente com a perspectiva mimética. Supõe-se que tal comportamento se deve à busca por legitimidade da entidade no mercado. Além disso, a interação característica da indústria química brasileira com o mercado internacional e o contato com as práticas de empresas líderes no campo também pode contribuir para acentuar o mecanismo de isomorfismo mimético.

\section{Fundacentro}

Outros 11 trechos com características miméticas foram creditados ao representante da Fundação Jorge Duprat Figueiredo de Segurança e Medicina do Trabalho (Fundacentro), ligada ao Ministério do Trabalho e Emprego, Gilmar Trivelato. Assim como a representante da Abiquim, o representante da Fundacentro acredita que a existência de determinadas práticas adotadas internacionalmente deve ajudar o Brasil na definição de seu novo quadro institucional em segurança química. Segundo ele, "o trabalho de classificação de substâncias químicas no Brasil será facilitado pois, internacionalmente, já existe uma relação harmonizada de substâncias classificadas, como o CLP ("Classification, Labelling and Packaging”), que é a internalização do GHS na União Europeia" e "portanto, o Brasil, além de não estar inovando, poderia fazer uso dos dados que já foram produzidos e estão disponíveis em outros países".

Em relação ao uso e produção das substâncias químicas, o representante propõe que a regulação brasileira tenha o mesmo escopo do REACH, adotado pela União Europeia, e do GHS, em que produtos acabados que têm exposição humana intencional possuem regulação específica. Seguindo esse raciocínio, cosméticos, medicamentos e agrotóxicos ficariam de fora do escopo do anteprojeto, mas, segundo Trivelato, as substâncias utilizadas em sua fabricação devem ser controladas. Ainda com base nos regulamentos da União Europeia e de outros países, o representante 
apresentou propostas para definições a serem incluídas no projeto de lei referentes aos termos "substâncias químicas", "misturas", "impurezas", "aditivos", "produtos químicos", entre outros.

Quanto ao limite de volume de produção e de importação de substâncias para que as empresas sejam obrigadas a reportar no inventário, mais uma vez o representante se apoia em referenciais externos: "Na União Europeia, por exemplo, esse corte é de 1 tonelada/ano, ou seja, quem produz ou importa uma quantidade inferior a essa não tem a obrigação de se registrar no REACH, a não ser que a substância tenha características perigosas."

Práticas internas de outros órgãos brasileiros também orientaram o posicionamento do representante da Fundacentro. Como ponto de partida para criação do cadastro nacional de substâncias químicas, por exemplo, ele sugere que "o Cadastro Técnico Federal (CTF- Ibama) pode ser espelhado e adaptado para as necessidades de construção de um novo cadastro para o inventário e para o controle propriamente dito, objeto da regulação", como também havia sido sugerido pela representante da Abiquim.

\section{$M M A$}

Como nos discursos das duas entidades anteriores, o isomorfismo mimético também esteve presente nas contribuições dos representantes do Ministério do Meio Ambiente às reuniões do GT. Para Alberto da Rocha Neto: “o fato do CTF já ser um sistema consolidado, cujo preenchimento já é obrigatório, poderia facilitar a aprovação da lei e a diminuição dos custos com a sua implementação." Ele também apresentou a ideia de se realizar um seminário com representantes de outros países que já estruturaram ou estão estruturando sistemas de segurança química, com a possibilidade de que em paralelo ao evento ocorra um workshop sobre o tema.

Durante as discussões sobre os termos do cadastro e avaliação de substâncias químicas, o MMA ficou incumbido de "buscar na legislação europeia e canadense os valores utilizados para determinar se uma substância possui características de persistência, bioacumulação, toxicidade, e de muita persistência e muita bioacumulação." A representante da entidade, Marília Almeida, destacou ainda que "podemos pensar numa forma de também adotar um controle mais específico sobre as substâncias mais perigosas, aos moldes do que o REACH faz para as SVHC (substances of very high concern)".

\section{Comentários gerais do GT (sem entidade definida)}

A busca por referenciais internacionais para balizar o anteprojeto de lei de substâncias químicas nacionais foi o principal ponto de consenso entre os participantes. Em um breve resumo sobre as discussões advindas de cada ponto de convergência do GT, a "importância e necessidade de utilizar referências e dados disponíveis no cenário internacional" aparece em primeiro lugar, sendo sugerido "acrescentar ao final da frase o trecho" "...de fontes reconhecidamente confiáveis". Com isso, o grupo resolveu compilar "fontes confiáveis, de preferência com as potencialidades de cada uma" com a finalidade de "descrever como utilizar os bancos de dados oficiais de outros países e como inserir no projeto de lei para orientar aqueles que serão regulados, elaborar guias, entre outras ações."

Também consta nas memórias que, para aprofundar o conhecimento sobre a regulação em outros países, foi elaborado um estudo comparativo entre os modelos de gestão de substâncias químicas adotados na União Europeia, Canadá e China, realizado por uma consultoria internacional contratada pela Ação "Controle e Regulação de Substâncias Químicas", no âmbito do Projeto Diálogos Setoriais. 


\section{MDIC e Ibama}

O representante do Ministério da Indústria, Comércio Exterior e Serviços (MDIC), Marcus Simões, sugeriu "utilizar a lista de 200 substâncias identificadas pelo Canadá como preocupantes, e internalizá-la no Brasil como prioritárias para adoção de medidas de controle específicas", "com o intuito de clarificar o cenário nacional e orientar as decisões do GT".

Também focada no referencial externo, a representante do Ibama, Karina de Oliveira Cham, defendeu que o cadastro abranja todas as substâncias, citando o exemplo do Canadá "em que todas as substâncias passam por avaliação ambiental, seja por legislação específica de químicos, de meio ambiente ou de saúde."

\subsection{Categoria de isomorfismo normativo}

A análise de conteúdo das memórias do GT revelou 26 unidades referenciais para a categoria em questão: 3 associadas a comentários gerais do GT; 6 associadas à Fundacentro; 12 à Abiquim; 4 ao MDIC e 1 à Fboms.

\section{Comentários gerais do GT}

Entre os comentários gerais atribuídos ao GT, identificamos 3 unidades referenciais que se encaixam nesta categoria de isomorfismo. A respeito da estruturação da legislação nacional e arranjos institucionais para a gestão de produtos químicos, incluindo medidas para a alocação de recursos necessários, os participantes do GT mencionam que:

- "É preciso, além de uma norma para controle de substâncias químicas de uso industrial, construir uma Política Nacional de Segurança Química, associada ao fortalecimento da CONASQ, para o pleno desenvolvimento de ações mais estratégicas"

- "O guia do Pnuma Lira Guidance (Guia para o Desenvolvimento de Infraestruturas Legais e Institucionais para a Gestão Segura de Produtos Químicos e Medidas de recuperação de custos da Administração Nacional) é uma ferramenta que orienta os países em como devem se estruturar para formular sua política interna relativa ao controle de químicos, incluindo mecanismos financeiros de recuperação de custos".

"Todas as instituições do GT devem sistematizar, dentro de sua área de competência, a importância dessa lei e em que ela poderia ser aplicada no seu contexto, ou seja, qual a perspectiva das instituições com essa lei. Ainda, sugestões de quais os mecanismos devem ser criados e quais seriam as competências de cada instituição".

\section{Fundacentro}

A partir da análise das memórias das reuniões do GT, as 6 unidades referenciais que se encaixam na categoria de isomorfismo normativo foram associadas à organização Fundacentro, ligada ao Ministério do Trabalho e Emprego (MTE). O representante Gilmar Trivelato defendeu a implementação do Sistema Globalmente Harmonizado de Classificação e Rotulagem de Produtos Químicos (GHS) que, segundo ele, "é a base para a gestão desses produtos". Ele também destacou que "é necessário gerar muitos guias e materiais de apoio para auxiliar o setor regu- 
lado no cumprimento da norma". Mais de uma vez destacou a importância do assunto para a entidade que representa, mencionando a intenção da Fundacentro de participar da avaliação da regulamentação em construção: "O Ministério do Trabalho e Emprego está disposto e aberto a avaliar as normas regulamentadoras relacionadas ao controle de substâncias químicas, quando necessário, tendo em vista a superveniência do marco legal proposto"; "a Fundacentro também entende que o projeto de lei deve abarcar os perigos relacionados às substâncias em todo o seu ciclo de vida, incluindo o ambiente de trabalho". No entender do representante da Fundacentro, não há como excluir a preocupação com a saúde e segurança no ambiente de trabalho, "pois o GHS também se aplica a esse cenário expositivo".

$O$ isomorfismo normativo também foi observado em dois dos principais pontos de desencontro do GT: um deles trata da criação do comitê técnico de avaliação de substâncias químicas (com a função de selecionar e avaliar, quanto ao risco ao meio ambiente e à saúde humana as substâncias químicas industriais constantes no cadastro); o outro ponto refere-se à instituição do comitê deliberativo de substâncias químicas, responsável pelas medidas de controle de risco a serem implementadas. Em relação a este segundo ponto, o representante da Fundacentro afirmou que "o órgão federal responsável pelo setor "trabalho" deve fazer parte do rol de instituições que serão responsáveis por selecionar as substâncias mais perigosas e estabelecer medidas de controle e gestão de risco, de acordo com as condições dispostas no PL". Também comentou que as regulações relativas ao ambiente de trabalho são de responsabilidade exclusiva do MTE, e que, por isso, o ministério deveria estar representado no comitê. A proposta não foi acolhida por unanimidade no GT, ao que o representante manifestou desagrado, destacando que "o posicionamento formal da Fundacentro e do Ministério do Trabalho e Emprego é que o setor trabalho esteja representado no referido Comitê."

\section{Abiquim}

A análise dos textos revelou 12 unidades referenciais de caráter normativo associadas à Abiquim. Nas discussões a respeito das definições sobre produto, elemento e substância química, a representante da Abiquim sugeriu repetidas vezes que a nova regulação utilize um termo que "seja entendido pela indústria e governo". Para identificar as substâncias químicas, Nícia Mourão propôs que se adote o seu número CAS (número de registro único designado às substâncias no banco de dados do Chemical Abstracts Service, uma divisão da Chemical American Society), que é usado internacionalmente. "Toda substância tem um número CAS e também muitos dos aqui chamados produtos. Então vale a pena nos basearmos nesta classificação".

Conforme a memória das reuniões do GT: "A Sra. Nícia Mourão sugeriu que tudo que tenha número CAS seja considerado substância para o escopo do $\mathrm{PL}$, pois isso facilitaria o trabalho, uma vez que, assim, se estaria trabalhando com substâncias químicas conhecidas." Atualmente, segundo a representante, existem mais de 81 milhões de substâncias orgânicas e inorgânicas registradas no CAS, e aproximadamente 15 mil novas substâncias são registradas diariamente.

O GT também debateu intensamente sobre se o inventário deveria conter o cadastro de misturas ou somente das substâncias que as compõem, tendo em vista que muitas misturas não possuem número CAS. Sobre isso, a representante da Abiquim "informou também que muitas empresas que importam substâncias químicas não recebem do exportador a informação da composição da mistura, por se tratar de um dado sigiloso e estar sob nome fantasia, sendo a formulação um segredo da empresa." Na sequência, reforçou que "se for exigido aos exportadores de misturas que forneçam sua formulação, é possível que deixem de vender para o Brasil." Preo- 
cupada com possíveis limitações ao comércio do setor, a representante defendeu que o cadastro contenha apenas substâncias consideradas perigosas que compõem as misturas dos produtos importados, e não todas as substâncias da composição. Segundo ela, "há o importador que traz o produto que concorre com o nacional e aquele que importa para utilizar em sua produção não havendo similar nacional, nesse caso, não deveria haver barreira para a importação".

Com o intuito de facilitar a construção do inventário brasileiro de substâncias químicas, a representante da Abiquim fez apresentação sobre a Tarifa Externa Comum do Mercosul (TEC) e sobre a composição das Nomenclaturas Comuns do Mercosul, que compõem principalmente a indústria química.

Também houve intenso debate sobre se seria suficiente nomear a legislação de "controle de substâncias químicas", excluindo o termo "uso industrial", ao que a representante da Abiquim informou que sua consultoria jurídica a respeito da definição e delimitação do termo "uso industrial". Nas discussões sobre possíveis penalidades a quem descumprisse o estabelecido na nova lei, a representante recorreu mais uma vez a sua consultoria jurídica, colocando mais uma vez em evidência o isomorfismo normativo.

Em outro movimento relacionando à profissionalização e ao isomorfismo, a representante demonstrou apoio à educação formal e criação de uma base de compartilhamento de práticas, propondo uma "organização de suporte e a necessidade de formação de especialistas em todos os níveis". Nesse sentido, ela demonstrou especial preocupação com pequenas empresas: "É preciso também um programa de governo para as pequenas empresas, incluindo principalmente treinamento".

A necessidade de treinamento formal para tornar bem sucedida a transformação organizacional revela-se um forte indicador de isomorfismo normativo. A representante da Abiquim defende que "tem que dar às empresas responsabilidade de arcar com o conhecimento contido". Lembrou, contudo, que há um acordo entre as empresas de confidencialidade e que iria verificar internamente o que pode ser fornecido. Atenta ao modus operandi do setor, Nícia defendeu ainda que o "cadastro inicial não deve contemplar informações de possíveis usos das substâncias, isso ficaria para um segundo momento, pois é muito difícil para as empresas descobrirem pra que as substâncias vendidas serão utilizadas por aqueles que as compram."

Observa-se, assim, que a questão normativa é bastante presente nas sugestões da representante da Abiquim, possivelmente pela intensa participação do setor químico e da Associação que o representa no mercado internacional.

\section{$M D I C$}

Verificou-se também o comportamento de isomorfismo normativo por parte do representante do Ministério da Indústria e Comércio exterior, Marcus Simões. Foram identificadas 4 unidades referenciais para essa categoria. Assim como outros participantes, o representante do MDIC julgou "necessário desenvolver o conceito de nomenclatura para o inventário nacional e alinhar as classificações alfandegárias." Em relação ao ponto de diferenciação de obrigações entre importadores e produtores, defendida pela Abiquim, Simões (MDIC) afirmou que não deveria haver distinção entre a exigência ao produtor nacional e ao importador, ressaltando que "setor químico está passando por um momento crítico de participação das importações" e que "é um momento importante para se refletir sobre a criação de uma barreira técnica que auxilie mais o produtor nacional frente à concorrência desleal com o produto importado de má qualidade". Segundo ele, "qualquer eventual obrigação administrativa que alcance o importador de substâncias químicas e que venha a ser criada pela nova lei, precisaria ser estendida para o mercado nacional 
(produtores e compradores), para que não haja infração da regra de Tratamento Nacional da OMC (Organização Mundial do Comércio)". Nota-se que o representante busca legitimar sua organização por meio da atuação confiável, cumprindo leis, normas e regras.

Em outro momento, Roberto Loureiro Filho, também representante do MDIC, solicitou a inclusão do setor "indústria e comércio exterior" entre as instituições que integrarão a comissão responsável pela seleção das substâncias químicas mais perigosas, destacando que "será necessária a realização de análises socioeconômicas (impacto no setor industrial, nos empregos e no comércio exterior) que devem parametrizar a seleção das substâncias". Houve desacordo nesse ponto. Os representantes do Fórum Brasileiro de ONGs e Movimentos Sociais para o Meio Ambiente e o Desenvolvimento (Fboms) e da Central Única dos Trabalhadores (CUT) destacaram suas preocupações com a inclusão do setor indústria e comércio exterior, justificando que "os processos de seleção das substâncias e de estabelecimento das medidas de controle e gestão de risco poderiam sofrer influências políticas, priorizando as conclusões da análise socioeconômica à ambiental e de saúde". Em defesa de sua entidade, o representante do MDIC respondeu que "a análise socioeconômica deverá abordar pontos importantes, como os possíveis impactos ao setor, impactos nos empregos, necessidade e viabilidade de substituição de tecnologias e matérias primas, desenvolvimento regional", acrescentando, ainda, que o Ministério desenvolve suas atividades "levando em consideração não apenas os aspectos da indústria e comércio exterior, como também aqueles relacionados ao trabalho, meio ambiente e saúde". A inclusão do setor de indústria e comércio no grupo que irá definir as substâncias a serem controladas foi apoiada pela representante da Abiquim.

\section{Fboms}

Da mesma forma que os representantes da Fundacentro e do MDIC defenderam a inclusão de suas organizações nos comitês de gestão de substâncias químicas, a representante do Fórum Brasileiro de ONGs e Movimentos Sociais para o Meio Ambiente e o Desenvolvimento comentou que "a sociedade civil deveria estar representada no rol das instituições". Este comentário foi rebatido pelo representante do MMA, Alberto da Rocha Neto "por tratar-se de uma atividade de regulação iminentemente de caráter estatal e que os setores da sociedade civil estão presentes em outros fóruns, como a Conasq, e que os setores aos quais representam estão representados pelos respectivos Ministérios setoriais".

\section{CONSIDERAÇÕES FINAIS}

Por meio deste artigo, pretendeu-se identificar os motivadores para a criação do anteprojeto de lei nacional de substâncias químicas industriais, que dispõe sobre o cadastro, a avaliação e o controle de substâncias químicas industriais. A análise de conteúdo das memórias do grupo de trabalho instituído no âmbito da Comissão Nacional de Segurança Química revelou a existência de uma articulação entre os três mecanismos de isomorfismo - coercitivo, mimético e normativo - na construção na nova legislação. O peso de cada mecanismo, contudo, variou tanto em relação aos temas tratados quanto em relação às necessidades e interesses das instituições que integraram o GT. Partindo da abordagem institucional, na qual se verifica que valores e interesses organizacionais prevalecem, notou-se que a agenda de segurança química foi em grande medida pautada pelo isomorfismo mimético, em meio a um cenário de crescentes incertezas e preocupações regulatórias. 
Ao longo das reuniões, a Associação Brasileira da Indústria Química (Abiquim) foi a organização que mais atuou com o pilar mimético, principalmente em relação às práticas internacionais, de forma a legitimar-se por meio da atuação confiável, tendo em vista que a constante interação com o ambiente internacional por parte das indústrias químicas brasileiras facilita o fluxo de informações bem como a adequação de práticas internacionais para realidades locais. Ela é seguida pela Fundação Jorge Duprat Figueiredo de Segurança e Medicina do Trabalho (Fundacentro), ligada ao Ministério do Trabalho e Emprego e pelo Ministério do Meio Ambiente. Juntas, essas organizações acabaram por guiar o GT na busca pela legitimação por meio de linhas de ação orientadas pelo contexto, regras e significados institucionalizados no setor químico. Dessa forma, o mecanismo mimético foi o mais preponderante na construção da normativa de segurança química em questão. Em segundo lugar, aparece o isomorfismo normativo, com seu formalismo que homogeneíza e institucionaliza critérios, definições e normas em busca de legitimação. Abiquim, Fundacentro e Ministério da Indústria, Comércio Exterior e Serviços foram as três organizações que mais evidenciaram este mecanismo.

Em terceiro lugar aparece o mecanismo de isomorfismo coercitivo, verificado nas pressões ambientais crescentes e tendências de gestão em segurança química, bem como em marcos internacionais, como a Agenda 21, a Cúpula de Joanesburgo (Rio +10) e a Estratégica Internacional para a Gestão de Substâncias Químicas (SAICM - Strategic Approach to International Chemicals Management).

Para DiMaagio e Powell (2005), dado que o efeito do isomorfismo institucional é a homogeneização, o melhor indicador de mudanças isomórficas é a redução em variação e diversidade, que pode ser medida por menores desvios padrão nos valores de indicadores selecionados em um grupo de organizações. O presente estudo verificou que, apesar da complexidade do tema de segurança química, houve poucas divergências no GT, e quando alguma proposta desviava do padrão isomórfico, rapidamente era rebatida, como quando a representante do Fórum Brasileiro de ONGs e Movimentos Sociais para o Meio Ambiente e Desenvolvimento sugeriu a participação da sociedade civil nos comitês de gestão de substâncias químicas e a inclusão no escopo de substâncias a serem reguladas dos nanomateriais, cuja aplicação em cosméticos, fármacos e outros produtos tem gerado preocupação do ponto de vista da saúde ambiental. À luz da perspectiva teórica adotada, na medida em que o pluralismo é um valor de orientação nas deliberações políticas públicas, é necessário promover formas de coordenação intersetorial que estimulem a diversificação em vez da homogeneização precipitada.

A menor inserção de setores cruciais para o debate da questão, como o da saúde e o do meio ambiente, são outro ponto de preocupação tendo em vista a natureza da questão, que tem efeitos amplos e indiscriminados nesses campos. O resultado dessa fragmentação administrativa, segundo o cientista político Neil Carter, é que políticas implementadas não refletem a complexidade das interações socioambientais, mas os interesses corporativistas de agentes econômicos que são resguardados pelos respectivos setores governamentais (CARTER, 2007). A partir da análise do material, também se verificou que o debate foi fortemente permeado por uma perspectiva tecnocêntrica, que não faz jus à complexidade dos riscos e incertezas associados às substâncias químicas e que expõem indistintamente toda a coletividade.

Com isso, esta pesquisa buscou trazer uma contribuição para os estudos organizacionais relacionados ao avanço da agenda de segurança química no país. Embora a questão tenha gerado demandas e responsabilidades para o governo brasileiro e para os gestores públicos, e a resposta ao desafio venha se dando com movimentos voltados à expansão de medidas regulatórias, fica em aberto uma indagação: dado que o isomorfismo nem sempre leva à maior eficiência, será que 
essas mudanças, da forma como têm se dado, de fato propiciam melhor gestão do risco das substâncias químicas de forma a reduzir ameaças à saúde humana e ambiental ou trata-se apenas de mecanismos de proteção isomórfica? Esta é uma questão que se coloca para os estudos sobre segurança química e governança ambiental, e cujas respostas passam por uma análise crítica dos mecanismos institucionais que estão na gênese das normativas nacionais. Neste sentido, outras abordagens teórico-analíticas, como as das teorias sociais de risco, podem oferecer interpretações valiosas para a compreensão desses processos.

\section{REFERÊNCIAS}

ABELKOP, A. D. K.; GRAHAM, J. Regulation of Chemical Risks: Lessons for Reform of the Toxic Substances Control Act from Canada and the European Union. Disponível em: http://bit. Iy/2v3jEPG. Acesso em: 11 jun. 2017.

ALBUQUERQUE FILHO, B.; MACHADO DA SILVA, C. L.

Práticas organizacionais e estrutura de relações no campo do desenvolvimento metropolitano. RACRevista de Administração Contemporânea, v. 13, n. 4, 2009.

ALMEIDA, G. A.; Weber, R.R. Fármacos na represa Billings. Rev. Saúde e Ambiente, v.6, n.2; p. 7-13, 2005.

ALVES, Zélia Mana Mendes Biasoli e SILVA, Maria Helena. Análise qualitativa de dados de entrevista: uma proposta. Paidéia (Ribeirão Preto) 2 (1992): 61-69.

BARDIN, L. Análise de conteúdo. Lisboa: Edições 70, 1977.

BARRA, Geraldo Magela Jardim. THE PROCESS OF COORDINATION IN THE AGROINDUSTRIAL SYSTEM OF SPECIALTY COFFEE. Informe GEPEC, v. 21, n. 2, p. 131-146, 2017.

BRASIL, Ministério do Meio Ambiente. Anteprojeto de Lei sobre Substâncias Químicas Industriais. Disponível em: <http://hotsite.mma.gov.br/consultasubstanciasquimicas/conheca-a-proposta> [acesso em 8 out 2017]

BRASIL, Ministério do Meio Ambiente. Fundamentação e elementos técnicos para o anteprojeto de lei que dispõe sobre o cadastro, a avaliação e o controle de substâncias químicas industriais. Brasília, 2016. Disponível em: <http://bit.ly/2t8eTXY>. Acesso em: 13 jun. 2017.

BRASIL, Ministério do Meio Ambiente. Memórias das reuniões do GT Regulação de Substâncias Químicas - CONASQ. Disponíveis em: <http://bit.ly/2t9vVVt> Acesso em: 01 jun.2017.

BRAUSCH, J. M.; RAND, G. M. A review of personal care products in the aquatic environment: Environmental concentrations and toxicity. Chemosphere, v. 82, n. 11, p. 1518-1532, 2011.

CARTER, N. The Politics of the Environment: Ideas, Activism, Policy. Cambridge University Press, 2001.

COLBORN, T.; DUMANOSKI, D.; MEYERS, J. Our Stolen Future: Are we threatening our fertility, intelligence and survival: A Scientific Detective Story. Nova York: Dutton, 1996. 
DAMSTRA et al. 2002; Global Assessment of the State - of - the Science of Endocrine Disrupters. World Health Organization - International Programme on Chemical Safety, 2002.

DE MELO PEREIRA, Fernando Antonio. A evolução da teoria institucional nos estudos organizacionais: um campo de pesquisa a ser explorado. Revista Organizações em Contexto, v. 8, n. 16, p. 275-295, 2012.

DIMAGGIO, P. J.; POWELL, W. A gaiola de ferro revisitada: isomorfismo institucional e racionalidade coletiva nos campos organizacionais. Revista de Administração de Empresas, São Paulo, v. 43, n.2, p. 74-89, abr/jun, 2005.

DIMAGGIO, P. J.; POWELL, W.; The New Institutionalism in Organizational Analysis. University of Chicago Press, 1991.

FALCONER, I. R. et al. Endocrine-disrupting compounds: A review of their challenge to sustainable and safe water supply and water reuse. Environ. Toxicol., v. 21, n.2, p. 181-191, 2006.

GHISELLI, G.; JARDIM, W. F. Interferentes endócrinos no ambiente. Quim. Nova, Campinas, v. 30, n. 3. p. 695-706, fev. 2007.

GODOY, A. S. Introdução à pesquisa qualitativa e suas possibilidades. Revista de administração de empresas. São Paulo, v. 35, n.2, 1995, p.57-63.

CAMPOS, C. J. G. Método de análise de conteúdo: ferramenta para a análise de dados qualitativos no campo da saúde. Revista Brasileira de Enfermagem, Brasília, v. 57, n.5, p. 611-614, 2004.

HOFFMAN, A. J. Institutional evolution and change: Environmentalism and the US chemical industry. Academy of Management Journal. v. 42, n.4, p.351-371, 1999.

KORTENKAMP, A. Ten years of mixing cocktails: a review of combination effects of endocrinedisrupting chemicals. Environmental health perspectives, v. 115, n.1, p. 98, 2007.

LI, C.; ANASTAS, P. Green Chemistry: present and future [editorial]. Chem. Soc. Rev, v. 41, p.14131414, 2012.

MITRO, S. D., et al. Consumer product chemicals in indoor dust: a quantitative meta-analysis of US studies. Environmental Science \& Technology v. 50, n. 19, p. 10661-10672, 2016.

NEVES, J. L. Pesquisa qualitativa: características, usos e possibilidades. Caderno de pesquisas em administração, São Paulo, v. 1, n. 3, 1996.

UNITED NATIONS. Environment Programme, Agenda 21. Chapter 19 - Disponível em:

<ht t p://staging.unep.org/Documents. Multilingual/Default. asp?Document ID=52\&ArticlelD=67\&I=e $n>$ Acesso em: 11 jun. 2017.

WHO/UNEP. State of the science of endocrine disrupting chemicals - 2012. An assessment of the state of the science of endocrine disruptors prepared by a group of experts for the United Nations Environment Programme (UNEP) and WHO. Geneva: WHO/UNEP, 2013. Disponível em: < http:// www.who.int/ceh/publications/endocrine/en/ >. 